\title{
Boşanma Sürecinde Ortak Ebeveynlik ve Ortak Velayete İlişkin Bir Derleme
}

\author{
DOI: 10.26466/opus.970966
}

\author{
Ayșegül Sayan Karahan * \\ * Dr, Türkiye Adalet Akademisi, Ankara/Türkiye \\ E-Posta: pskaysegulsayan@hotmail.com \\ ORCID: 0000-0002-5580-0617
}

\section{Öz}

Çocuk yetiştirme, çocuğun gelişimsel gereksinimlerinin karşılanması açısından her ikisi de farklı özelliklere ve öneme sahip ebeveynin ekip çalışması olarak ilgi gören bir çalışma alanı olagelmiştir. Yaşanan toplumsal değişimlere bağll olarak boşanma oranları artmakta, kadınların işgücüne ve erkeklerin çocuk bakımına katılımı yaygınlaşmaktadır. Bu değişimler doğrultusunda, yeni gelişen kavramlar olarak ortak ebeveynlik ve ortak velayet konularmda mevcut tabloyu ortaya koyan ve daha ileri araştırmalara gereksinim olduğu görülmektedir. Bazı ülkelerde ortak velayet uygulanmaktayken Türkiye'de uygulanabilirliği tartışılmaktadır. Bu derleme çalışmasında, ortak velayetin hangi koşullarda etkililiğinin arttığının ve hangi koşullarda dezavantajlar doğurabileceğinin vurgulanması amaçlanmıştır. Ortak velayetin, ebeveynlerle ilişki ve kaynakların sürdürülmesi açısından avantajları vurgulanırken diğer yandan sürekli değişimlerin yaşanması nedeniyle stabiliteye zarar verebilmesi ve boşanmış ebeveynlerin sürekli bağlantısını gerekli kılması gibi dezavantajları bulunmaktadır. Boşanma öncesi ebeveyn çocuk ilişkilerinin nitelikli olduğu ve ebeveynler arası çatışmalardansa işbirliğinin olduğu durumlarda ortak velayetin fayda sağladığı, aksi durumlarda ve ihmal, istismar, şiddet ya da psikopatolojinin varlı̆̆ı gibi durumlarda ise faydadan çok zarara yol açabileceğ $i$ vurgulanmaktadır.

Anahtar Kelimeler: Ortak Ebeveynlik, Ortak Velayet, Boşanma. 


\title{
A Review Regarding Coparenting and Joint Custody in Divorce Process
}

\begin{abstract}
Childrearing has been an area of interest as a teamwork of parents, both of whom have different characteristics and importance in terms of meeting the developmental needs of the child. Due to social changes, divorce rates are increasing, women's participation in the labor force and men's participation in childcare is widespreading. Due to these changes, descriptive and further research is needed on coparenting and joint custody, as emerging concepts. While joint custody have been practiced in some countries, the applicability in Turkey is under discussion. In this review, it is aimed to emphasize the conditions regarding the effectiveness of joint custody. Joint custody contributes to the maintanance of the relationship and resources with parents, while damaging stability due to the reccurent changes and requiring ongoing connection between parents. Joint custody benefits in cases of qualified pre-divorce parent-child relationship, cooperation rather than conflict between parents; presence of neglect, abuse, violence and psychopathological conditions.It is emphasized that otherwise it can be harmful.
\end{abstract}

Keywords: Coparenting, joint custody, divorce. 


\section{Giriş}

Kadın ve erkeğin çift ilişkisine ortak bir çocuğun katılması yoluyla bireyler ebeveyn olmaktadır. Bir çocuğun dünyaya gelmesi biyolojik olarak bir kadın ve bir erkeğin birlikteliğinden kaynağını almaktadır. Buna ek olarak kadın ve erkeğin ebeveynlik özellikleri toplumsal ve psikolojik açılardan farklılık gösterebilmektedir. Dolayısıyla ebeveynlik biyo-psikososyal bir olgu olarak ele alınabilmektedir. İçine doğduğu ve yetiştiği aile sistemindeki ilişkiler ağı çocuk için dünya ve ilişkileri anlama çerçevesi sağlamaktadır, dolayısıyla ebeveynlerin, ebeveyn-çocuk ilişkisinin ve ebeveynler arası ilişkilerin niteliği çocuğun tüm hayatı için belirleyici olabilmektedir.

Kadın ve erkek arasındaki çift ilişkisi sonlandırılabilir bir ilişki türü olmakla birlikte ortak bir çocuğa sahip olmakla oluşan ebeveynlik ilişkisi geri dönüşü olmayan bir ilişki biçimidir. Ortak bir çocuğa sahip olan kadın ve erkeklerin ebeveynlik bağları her koşulda sürmektedir. Ortak bir çocuğa sahip kadın ve erkeğin evliliğini sonlandırması yani boşanması durumunda ise ebeveynliğin hukuki açıdan da ele alınması gerekmektedir.

Çocukların farklı nitelikteki gereksinimlerin karşılanması için hem anne hem de babaya olan ihtiyacı aile birliğinin sürmemesi yani boşanma durumunda da devam etmektedir. Çocukların aile birliği içinde hem anne hem de baba modeli ile yetişebilmesi beklenen en ideal aile düzenlemesi olsa da, boşanma bazı ebeveynler için bir tercih, bazıları içinse daha sağlıklı bir gereklilik olarak deneyimlenebilmekte ve boşanma oranları yaygınlaşmaktadır. Boşanma, ebeveynler için olduğu gibi çocuklar için de stres verici ve uyum sağlanmasını gerektiren bir dönem olarak yaşanabilmektedir. Bu değişim dönemini sağlıklı geçirebilmelerinde çocukların velayet düzenlemesi de önemli bir konudur. Tek ebeveynin velayeti üstlenmesi ve diğer ebeveynin çocukla kişisel ilişki kurması yaygın olan uygulama olmakla birlikte son yıllarda ortak velayet kavramı gündeme gelmektedir. Türk Medeni Kanununda ortak velayete ilişkin bir düzenleme yer almamakla ve daha önceki yıllarda ortak velayet kamu düzenine aykırı bulunmakla birlikte son yıllarda tarafların anlaşmaları halinde ortak velayete karar verilip verilemeyeceği tartışılmaya başlanmıştır. 
McHale (1995) ortak ebeveynlik kavramını ebeveynlik davranışında sorumluluk ve inisiyatif paylaşımı olarak tanımlamıştır. McHale (1995) ebeveynlerin evli, bekar ya da boşanmış da olsa ortak ebeveynlik yapabileceklerini ifade etmiştir. Ortak ebeveynlik devam eden evliliklerle ilişkili olarak ortaya çımış bir kavram olsa da 1990lı yıllardan itibaren sonlanan evliliklerle ilişkili olarak da ele alınmıştır. Ortak velayet, ortak ebeveynlik kavramının hukuki karşılığı niteliğindedir. Sosyolojik açıdan cinsiyet rollerinin değişmesi doğrultusunda giderek daha çok kişi için bir seçenek haline gelen ortak velayet ilgi odağı haline gelmektedir (Karataş, 2019).

Uzun yıllar boyunca ayrılık veya boşanma sonrası ebeveynlik planları hakkında kararlar anneyi çocuğun temel bakım vereni olarak gören geleneksel inançlardan etkilenmiştir. Annelerin daha fazla işgücüne katılımı ve babaların daha fazla çocuk bakım ilişkisine katılımı gibi toplumsal değişimlerin sonucu olarak bu durum artık değişmektedir (Steinbach, 2019).

Literatürde ve ülkemizde baba katılımı konusunda yapılan sınırlı sayıda çalışmalar hem ailenin daha iyi işlemesi hem de çocuğun gelişim alanlarında daha üst düzeye ulaşması açısından önemini göstermektedir (Kocayörük, 2010; Kuzucu, 2011; Lamb, 2000, Parke, 2000). Bir diğer deyişle anne ve baba ebeveynliği paylaştığında hem çocuk hem de aile daha işlevsel olmaktadır.

Ortak velayet savunucuları (Kruk, 2012; Warshak, 2014) boşanmış ebeveynlerin devam eden çatışmaları olsa bile, baba ile bağlantının buna değer olduğunu ileri sürmektedir. Diğer yandan, bazı araştırmacılar ise, ebeveynler arası devam eden çatışmanın çocuklar için zararlı olduğunu ve böyle bir durumda tek ebeveynin velayetinin daha uygun bir karar olacağını savunmaktadır (Emery, 2016; McIntosh, Pruett, ve Kelly, 2014; Pruett, McIntosh, ve Kelly, 2014).

Ortak velayete ilişkin durumun ortaya konması amacıyla bu derleme çalışmasında, ortak velayete ilişkin literatür gözden geçirilmiş, ortak velayetin avantaj ve dezavantajları ele alınmış, ortak velayetin diğer velayet düzenlemelerine göre etkililiğini değerlendiren bulgular özetlenmiş ve hangi koşullarda ortak velayetin faydalı olabileceği hakkında önerilerde bulunulmuştur. Yeni bir çalışma konusu olması 
nedeniyle bu derleme çalışması ile daha ileri araştırmalara olan gereksinimin vurgulanması amaçlanmıştır.

\section{Kuramsal Çerçeve}

Çocuk bakımı görev ve sorumluluklarının ebeveynler arasında paylaşımına ilişkin etkileşimler ortak ebeveynlik olarak tanımlanmaktadır (McLanahan ve Beck, 2010; Teubert ve Pinquart, 2010). İki ebeveynin de yapıcı, destekleyici ve karşılıklı olarak çocuk yetiştirme sürecine dahil olması olumlu sonuçlara yol açmaktadır (Katz ve Woodin, 2002; Teubert ve Pinquart, 2010). Ortak ebeveynlik görev ve sorumluluklukların eşitliğinden çok, rol ve sorumluluklar üzerinde uzlaşma sağlanmış olmasını ifade etmektedir (Egeren ve Hawkins, 2004).

Ortak ebeveynlik için bir çocuğun bakımı ve sorumluluğunu üstlenmek önemlidir (Amato ve Afifi, 2006; Egeren ve Hawkins, 2004; Sobolewski ve Amato, 2007). Feinberg (2002) bir çocuğun bakımını üstelenen kişilerin medeni durumunun önemli olmadığını belirtmektedir. Ortak ebeveynlik ilişkisi her tür ve yapıdaki ailede benzer şekilde oluşmaktadir.

Ortak velayet; giderek yaygınlaşan ve ayrıllk veya boşanma sonrası çocukların her bir ebeveynle zamanının en az \%25-50'sini geçirdiği bir yaşam düzenlemesi olarak tanımlanmaktadır. Ortak velayet iki açıdan genellikle anne tarafında olan tek ebeveynin velayetinden farklılaşmakta ve cinsiyet eşitliğini desteklemektedir. Bunlardan birincisi, velayet ve çocuk yetiştirme görevlerini tek başına yürütmektense kadının/annenin işgücüne katılımını desteklemek ve aşırı yüklenerek tükenmesini önlemektir. Bir diğeri ise erkeğin/babanın çocuğun günlük hayatına katılımını ve sorumluluklarını artırmak ve dolayısıyla babalık rollerinden mahrum kalmasını önlemektir. Ayrıca çocukların duygusal ve finansal kaynaklardan mahrum kalmasını önleyerek boşanmanın olumsuz etkilerini aza indirdiği bildirilmektedir (Spruijt ve Duindam, 2009).

Minuchin (1974) aile sisteminin çeşitli alt sistemler içerdiğini, ebeveynlik ilişkisinin diğer alt sistemlerden farklı fakat diğer alt sistemlerle ilişkili olduğunu ileri sürmüştür. Eşler arası ve ebeveyn-çocuk arasındaki ilişkiden farklılaşan ebeveynlik ilişkisi yine de bu alt sistemlerle bağlantılıdır (Feinberg, 2002; Feinberg, Kan ve Hetherington, 2007; 
Frank, Hole, Jacobson, Justkowski ve Huyck, 1986; Gable, Belsky ve Crnic, 1995; Hughes, Gordon ve Gaertner, 2004; Marriott, 2011).

Feinberg (2003) ortak ebeveynlik ilişkisinin "yetişkinlerin arasında çocukla ilişkili olmayan romantik, cinsel, arkadaşsal, duygusal, finansal ve yasal hususları" içermediğini belirtmiştir. Feinberg'in modelinde ortak ebeveynlik ilişkisi; ebeveyn destek/köstek, çocuk yetiştirme uzlaşması, iş bölümü ve ortak aile yönetimi olmak üzere 4 ana öğe ile tanımlanmıştır. Ebeveyn destek veya köstek öğesi ebeveynlerin birbirlerinin ebeveynlik yetkinlik ve güçlerine gösterdikleri destek, saygı ve güvenin derecesini ifade etmektedir. Çocuk yetiştirmede uzlaşma, ebeveynler arasında çocuk yetiştirmeye yönelik ahlaki ve kültürel değerler, disiplin ve sevgi gösterme yöntemleri ve çocuğun güvende tutulması konuları hakkında iletişim kurularak ortak bir paydada uzlaşılma derecesini göstermektedir. İş bölümü ise çocukları ilgilendiren maddi ya da sağlıksal konular ile çocuk yetiştirme ve eş işleri ile ilgili kararları kapsamaktadır. Modele göre iş bölümünün eşitliğindense konuşularak üzerinde uzlaşmaya varılan şekillerde yönetilmesi vurgulanmaktadır. Ortak aile yönetimi ebeveynlerin çatışma, üçgenleşme ve dengeli ilişkiler kurulması olmak üzere başarılması gereken üç önemli göreve dikkat etmelerini işaret etmektedir.

Ahrons (1994) işbirliği ve çatışma boyutlarına göre beş farklı ortak ebeveynlik stili önermiştir. Hem iletişim hem de ikili ilişki düzeyleri yüksek olanları sıkı dostlar (perfect pals), yüksek kalitede iletişimi ve vasat düzeyde ikili ilişkileri olanları işbirlikçi meslektaşlar (cooperative colleagues), az görüşen ve iletişimleri vasat olanları öfkeli katılımcılar (angry associates) ve hem iletişimi hem de ikili ilişkileri düşük olanları ise azılı düşmanlar (fiery foes) olarak tanımlamıştır. Bunların dışında hemen hemen hiç iletişimi kalmamış ebeveynleri ise dağılmış ikililer (dissolved duos) olarak adlandırmıştır.

Literatürde çeşitli çalışmalarda (Baum, 2003; Kruk, 1993; Whiteside, 1998) ileri sürülen dört temel ortak ebeveynlik stili bulunmaktadır. Çatışma, işbirliği ve üçgenleşme boyutlarına göre; işbirlikçi ortak ebeveynlik, çatışmalı ortak ebeveynlik, kopuk ortak ebeveynlik ve paralel ebeveynlik stilleri ileri sürülmüştür (Amato, Kane ve James, 2011; Ferrante, 2008; Maccoby, 1992). İletişim ve işbirliğinin yüksek, çatışma ve üçgenleşmenin düşük olduğu ebevyenler işbirlikçi olarak 
adlandırılmıştır (Amato vd., 2011; Maccoby, 1992). Çatışmanın yüksek, işbirliğinin düşük olduğu ebeveynler çatışmalı olarak tanımlanmıştır (Garber, 2004; Kelly, 2004). İletişim, birliktelik ve işbirliğinin oldukça düşük olduğu ebeveynler kopuk olarak ifade edilmiştir (Kelly, 2004). Paralel ebeveynlik ise ne çatışma ne de işbirliğinin olduğu fakat ebeveynliğin ebeveynlerce bağımsız olarak yerine getirildiği durumları ifade etmektedir (Furstenberg ve Cherlin, 1991).

\section{Literatür Taraması}

Literatüre bakıldığında, ortak ebeveynliğin çeşitli değişkenler açısından ele alındığı görülmektedir. Çocuğun yaşı (Schum ve Stolberg, 2007; Stright ve Bales, 2003), cinsiyet (Dush, Kotila ve Schpoee-Sullivan, 2011; McHale, 1995; Schum ve Stolberg, 2007), kişilik özellikleri (Baum, 2003; 2004), ekonomik durum (Dozier, Sollie ve Stack, 1993; Fagan ve Kaufman, 2015; Marriott, 2011), eğitim seviyesi (Dozier vd., 1993; Stright ve Bales, 2003) gibi faktörlerin ortak ebeveynlik ilişkisi üzerindeki etkileri bildirilmiştir.

Çocukların yaşı ve içinde bulundukları gelişim aşamalarına göre ebeveynlerin katılım düzeylerinin ve ortak ebeveynlik niteliğinin farklılık gösterdiği bildirilmektedir (Stright ve Bales, 2003). Kök ailenin eğitim seviyesi yükseldikçe bireylerin eşlerine ebeveynlikte daha fazla destek gösterdiği, ortak ebeveynlik dinamiklerinin kuşaklararası aktarılabileceği, bireylerin mesleki ve mali olarak yaşadıkları değişimlerin ebevynlikte verilen desteği etkilediği ileri sürülmektedir (Riina ve Feinberg, 2018).

Ebeveynlik ilişkisinin niteliğinde evlilik ilişkisinin kalitesi ve iletişim gibi ilişkiye dair faktörlerin de etkili olduğu bildirilmektedir (Kolak ve Volling, 2007; Kruk, 1993). Boşanmadan önce eşler arasındaki çatışmaya ilişkin özelliklerin, boşanma sonrası ortak ebeveynliğin nasıl olacağını etkileyebileceği ileri sürülmektedir. Çatışma düzeyi yüksek evlilikleri olan çiftlerin, boşanma sonrası ortak ebeveynlikte de çatışma düzeylerinin yüksek olduğu bildirilmektedir (Cooney, Hutchinson ve Leather, 1995; Mitcham-Smth ve Henry, 2007). Ebeveynlerin nasıl bir boşanma süreci deneyimledikleri de boşanma sonrası nasıl bir ebeveynlik ilişkisi kuracaklarını yordamaktadır (Baum, 2003; 2004; Bonach, 2005; Markham, 
Ganong ve Coleman, 2007; Russell, Beckmeyer, Coleman ve Ganong, 2016). Ebeveynlerden birinin yeni bir duygusal yakın ilişkiye girmesi durumunda ortak ebeveynlik ilişkisinin de risk altına girdiği bildirilmektedir (Aquilino, 1994). Buna ek olarak, ebeveynlerden birinin yeniden evlenmesi durumunda da ortak ebeveynlik ilişkisinin kalitesinin düştügü belirtilmektedir (Ahrons, 2007; Christensen ve Rettig, 1996).

Kişilik bozukluğu olanların boşanma sonrası ortak ebeveynliğe ilişkin daha fazla güçlük yaşadığı bildirilmektedir (Baum, 2004; Baum ve Shnit, 2003). Güvensiz bağlanmış olan ebeveynlerin sıklıkla çatışmacı ya da kopuk ortak ebeveynlik stillerini benimsedikleri ortaya konmaktadır (Dozier vd., 1993; Roberson, Nalbone, Heeker ve Miller, 2010; Roberson, Sabo ve Wickel, 2011).

Ortak velayetle ilişkili yürütülen araştırmaların bulgularına göre; diğer velayet düzenlemelerini deneyimleyen ebeveynler ile ortak velayeti uygulayanlar birbirlerinden demografik ve sosyoekonomik özellikler açısından farklılık göstermektedir. Ortak velayeti uygulayanların daha yüksek eğitim seviyesinde, daha yüksek gelir seviyesinde, daha düşük düzeyde çatışmalı, boşanma öncesi baba katılımının daha aktif olduğu, evleri birbirine daha yakın oldukları bildirilmektedir (Cancian, Meyer, Brown ve Cook, 2014; Cashmore, Parkinson, Weston, Patulny ve Katz, 2010; Juby, Lebourdais ve Gratton, 2005; Kitterød ve Lyngstad, 2012; Masardo, 2009; Sodermans, Matthijs ve Swicegood, 2013).

İşbirliği, çatışma ve üçgenleşme boyutları ortak ebeveynliğe ilişkin çeşitli araştırmalarda ele alınmıştır (Baum, 2003; Macie ve Stolberg, 2003; Margolin, Gordis ve John, 2001; Mullett ve Stolberg, 1999). Araştırma bulgularına göre; çocuklar için en fayda sağlayan ortak ebeveynlik stilinin işbirliğine dayanan ortak ebeveynlik olduğu (Macie ve Stolberg, 2003; Marriott, 2011; McHale, 1995), çocuklar için en zarar veren ebeveynlik stillerinin ise çatışmalı ve kopuk ortak ebeveynlik olduğu bildirilmektedir (Roberson vd., 2011; Umemura, Christopher, Mann, Jacobvitz ve Hazen, 2015). Ortak ebeveynlik ilişkisi aile içindeki ebeveynçocuk ve eşler arası gibi diğer ikili ilişkileri hem etkiler hem de bu ilişkilerden etkilenir niteliktedir.

Meta analiz bulgularına göre, ortak velayet altındaki çocuklar tek velayet altındaki çocuklara göre daha iyi uyum düzeyinde gözükmekte ve daha az ebeveynler arası çatışma bildirilmektedir (Bauserman, 2002; 
Baude, Pearson, ve Drapeau, 2016; Breivik ve Olweus, 2006; Carlsund, Eriksson, Löfstedt, ve Sellström, 2013; Cashmore vd., 2010; Jablonska ve Lindberg, 2007; Neoh ve Mellor, 2010; Nielsen, 2015, 2017; Shiller, 1986). Bazı araştırmalarda ise ortak velayetin daha düşük uyumla ilişkili bulgular1 rapor edilmektedir (McIntosh, Smyth, ve Kelaher, 2010; McIntosh, Smyth, Wells, ve Long, 2010). Bazı araştırmacılar çocuğun iki farklı ev arasında sürekli gidiş gelişinin istikrar ve güvenlik duygusuna zarar verebildiğini vurgulamaktadır (Goldstein, Freud, ve Solnit, 1973).

Boşanma sonrası uyumda çocukların yaşadıkları zorluklar; ilişki, destek ve kaynaklar açısından bir ebeveynin kaybı, ebeveynler arası çatışma ve azalmış ebeveynliktir. Ortak velayet ile ebeveynlikle ilgili bu zorluklar giderilebilmektedir fakat çocuk ebeveynler arası çatışmaya daha fazla maruz kalabilmektedir. Ortak ebeveynliği destekleyen argumanlar çocuğun her iki ebeveynle ilişkisini sürdürmesinin faydasına vurgu yaparken diğerleri ortak velayetin çocuğu devam eden ebevyn çatışmasına maruz bırakarak zarar verebileceğini ve çocuğun hayatındaki stabiliteyi bozabileceğini ileri sürmektedir (Bauserman, 2002).

Ortak velayet durumunda çocuklar stabiliteyi engeller şekilde sürekli üç tür değişikliğe maruz kalmaktadır. İlişkisel değişim, çocuğun anneyle ya da babayla ilşkisinin sürekliliğinin ayrılık periyodları tarafından sürekli kesintiye uğramasını ifade etmektedir. Mekansal değişim sürekli iki yerleşim yeri arasında gidip gelmeyi içermektedir. Çocuk yetiştirme değişimi ise çocuğun sürekli farklı yaşam düzeni, çocuk yetiştirme tutumu, değerleri ve uygulamaları arasında kalmasına karşılık gelmektedir (Baude, Sagnes, ve Zaouche-Gaudron, 2010).

Çocuk yetiştirme görevlerinde ebeveynlerin sürekli fikir alışverişinde bulunma, uzlaşma, plan yapma ve koordinasyon sağlamasının gerekmesi nedeniyle ortak velayet stres verici olabilmektedir. Buna ek olarak, çocukların kıyafet ve okul eşyaları gibi giderlerinin iki ev için de yedeklenmesi gereksinimi nedeniyle finansal yüklerin de daha fazla olmasına yol açabilmektedir. Ayrıca, evler arasında gidiş gelişlerin düzenlenmesi açısından ebeveynlerin görece olarak birbirlerine yakın yaşamalarını gerektirmektedir (Bauserman, 2012; Van der Heijden, Poortman, ve Van der Lippe, 2016).

Ortak velayetin hangi koşullarda daha etkili olduğuna ilişkin çeşitli araştırmalar yapılmıştır. Çocuğun yaşı ve buna ek olarak cinsiyetinin 
etkili bir faktör olduğu bildirilse de bu konuda birbirinden farklı bulgular bulunmaktadir (Bergstrom, Fransson, Modin, Berlin, Gustafsson ve Hjern, 2015; Spruijt ve Duindam, 2009). Poortman (2018) boşanma öncesi baba katılımının düşük olması durumunda ortak velayetin avantaj sağlamadığını, ancak boşanma öncesi baba katılımı orta ya da yüksek düzeyde ise çocukların düzenli bağlantıdan fayda sağladığını bildirmiştir. Çeşitli araştırmalar olumlu sonuçlarla ilişkili olan faktörün birlikte geçirilen zamanın miktarı olmadığını, fakat daha çok ebeveynliğin kalitesi olduğunu doğrulamaktadır (Hagquist, 2016; Sandler, Wheeler, ve Braver, 2013; Spruijt, de Goede, ve Vandervalk, 2004). Her ne kadar ebeveynlerin çatışmasız bir ortam sağlamayı başardığı durumlarda ortak ebeveynliğin daha etkili olduğu bildirilse de (Lee, 2002), eğer ebeveynler arası yüksek düzeyde çatışma varsa olumlu bir etkisi olmadığ 1 vurgulanmaktadır (Maccoby, Depner ve Mnookin, 1990). Johnston, Klein ve Tschann (1989) ortak velayet altındaki çocukların uyum problemleri geliştirme risklerini ele aldığı araştırmasında, çocuğun evler arasında gidiş geliş sıklığı ve ebeveynler arasındaki çatışmaya dahil edilme düzeyinin uyum güçlükleriyle ilişkili bulunduğunu bildirmiştir. Devam eden çatışmaların olduğu boşanmış ailelerde sık gidip gelme düzenlemelerinin ve ortak velayetin özellikle çocukları alıp bırakma sırasında sözel ve fiziksel agresyonda artışa yol açtığ 1 bildirilmektedir. Özet olarak, mevcut araştırmalar ortak velayetin tek ebeveynin velayetine kıyasla ve çoğu çocuk için daha yararlı olduğuna ilişkin tutarlı bulgular sağlayamamaktadır (Johnston, 1995).

\section{Tartışma, Sonuç ve Öneriler}

Hukuki olarak, çocukların her iki ebeveyniyle ilişkilerini hem fiilen hem de bir hak olarak sürdürmelerine yönelik olarak ortak velayet kararları çocuğun yüksek yararı düşüncesiyle verilmekte, buna paralel olarak ebeveynlerden de ortak ebeveynlik ilişkilerinde birbirlerini desteklemeleri beklenmektedir (Van Krieken, 2005). Walker (1993) ise evlilik çatışmalarına birlikte çözüm bulamayarak boşanmaya yönelmiş olan eski evli çiftlerin boşanma sonrası kısa sürede birlikte rolleri ve sınırları iyi çizilmiş bir ebeyenlik ilişkisini kurabilmelerini beklemenin gerçekçi olmadığını ifade etmektedir. Evlilik döneminde çatışmaların 
fazla olduğu, duygusal boşanmanın gerçekleşemediği ya da taraflardan birinin boşanmak istemediği, ayrılığa alışamadığı, ayrılığa ilişkin olumsuz duyguları işleyemediği, ayrılığı kabullenemediği durumlarda ortak ebeveynlik ilişkisi kurmanın daha da zor olabileceği bildirilmektedir (Vanderkool ve Pearson, 1983).

Bauserman (2002) taraflardan biri istismarcı ya da ihmalkarsa, ruh sağlığı ya da uyum problemleri yaşıyorsa, ebeveynler arasında çatışmalı bir ilişki ve iletişim varsa çocuğun sürekli maruz kalması zararı artıracağından ortak velayetin tercih edilmemesi gerektiğini ileri sürmektedir. Bir diğer deyişle, ortak velayet tüm boşanma durumlarına uyan bir model değildir. Dolayısıyla, hangi koşullar altında ve hangi çocuklar için ortak velayetin daha uygun olacağının tanımlanması gerekli görülmektedir (McIntosh, 2009; Vanassche, Sodemans, Matthyis ve Swicegood, 2013).

Ortak velayet kararının hangi durumlar için daha uygun olduğunun sağliklı değerlendirilmesinin yapılabilmesi amacıyla ortak velayete ilişkin bir model ve hangi ebeveynler için bu seçeneğin daha isabetli olduğunu yordamaya katkıda bulunabilecek değerlendirme araçlarının geliştirilmesi daha ileri araştırmalar için önerilebilir. Ortak velayetin uygunluğuna ilişkin yordamalarda bulunurken sadece kendini değerlendirme türünde ölçme araçlarının kullanılmasındansa örnek senaryolar ya da davranış provaları içeren çoklu kaynakların kullanılmasının daha etkili olabileceği düşünülmektedir. Türkiye'de henüz ortak velayet grubunu temsil eden geniş örneklemlere ulaşmak mümkün olmasa da nitel araştırmalar ile boşanma aşaması ya da sonrası sürecindeki ebeveynlerin ortak ebeveynlikle ilişkili yaşadıkları zorluklar, beklentiler, çözüm önerileri, tutumları gibi özelliklerinin değerlendirilmesi faydalı bulunmaktadır.

Ortak velayetin etkililiğine yönelik çalı̧̧malarda araştırma gruplarının özelliklerinin bulguları etkiliyor olabileceği rapor edilmektedir. Ortak velayeti temsil eden grupların az sayıda olduğu ve temsil edici nitelikte olmadığı, araştırmalarda kontrol ve karşılaştırma gruplarının yaygınlıkla bulunmadığı, boylamsal çalışmaların ve izleme çalışmalarının yapılmadığı görülmektedir. Ayrıca ortak velayetin olumlu sonuçlarının ortak velayetin kendisinden mi yoksa ortak velayeti tercih eden ailelelerin daha iyi işbirliği, daha az çatışma, psikolojik olarak daha 
sağlıklı ebeveynler olma gibi ayrılık öncesi özelliklerinden mi ya da daha yüksek eğitim ve gelir düzeyi gibi demografik özelliklerden mi kaynaklandığına dikkat çekilmektedir. Ortak velayet ancak iki tarafın da istek ve onayına bağlı bir düzenlemedir ve velayet düzenlemesi değişiklikleri yapılabilmektedir. Dolayısıyla ebeveynlerden birinin farklı yere taşınması ya da evlenmesi, yeterli işbirliğinin sağlanamaması ya da ortak velayetin çocuk için işe yarar olmaması gibi pragmatik nedenlerle 2 ila 4 y1l içinde ortak velayet düzenlemesinden tek ebeveynin velayeti düzenlemesine üçte bir oranında değişiklik yapıldı̆̆ı değerlendirilmesi gereken bir bulgudur (Maccoby ve Mnookin, 1992; Pearson ve Thoennes, 1990).

Türkiye'de ortak ebeveynlik konusunda çalışmalar yeni gelişmekte olduğundan sınırlı sayıda olsa da kültüre özgü olarak ortak ebeveynliğin ortaya konması gereksinimi bulunmaktadır. Türkiye'de yürütülecek ortak ebeveynliği ortaya koyan çalışmaların bulgularına dayanarak ortak ebeveynliğe yönelik psiko-eğitsel programlar gibi destekleyici sistemlerin geliştirilmesi fayda sağlayacaktır (Gürmen, 2019). Buna ek olarak, ortak ebeveynlik kavramının boşanma sürecindeki yasal karşılı̆̆ını ifade eden ortak velayet kavramı da yeni ve çalışılmamış bir kavramdır. Yasa yapıcıların ortak velayete ilişkin düzenlemeler geliştirmeleri için bu alanda yapılacak çalışmaların bulguları önemli görülmektedir. Ortak velayetin etkili olup olmadı̆̆ının ve hangi koşullarda etkili olup tercih edilebileceğinin belirlenmesi gerek hukuk alanında çalışan karar vericiler, gerek aile mahkemelerinde velayet konusunda sosyal inceleme raporu hazırlamakla görevlendirilen psikolog, psikolojik danışman ve sosyal hizmet uzmanları, gerekse de boşanma aşamasındaki ebeveynler ve çocukları için katkı sağlayacaktır. Ortak velayete karar verilmesi öncesi ya da sürecinde ebeveynlerin psikoeğitsel programlarla desteklenmesi ve gerekli durumlarda ek destek almalarının sağlanması, ayrıca izleme çalışmaları ile sürecin takip edilmesi önerilebilir. 


\title{
EXTENDED ABSTRACT \\ A Review Regarding Coparenting and Joint Cus- tody in Divorce Process
}

\author{
Ayşegül Sayan Karahan \\ Turkish Justice Academy
}

\begin{abstract}
Although the couple relationship between man and woman is a type of relationship that can be terminated, the parenting relationship formed by having a common child is an irreversible type of relationship. The parenting bonds of men and women who have a common child continue under all circumstances. In case that a woman and a man with a common child end their marriage, which is called as divorce, parenthood should also be considered from a legal point of view.

Although the sole custody, in which one parent gets the custody and the other parent establishes visitations have been the common practice, the concept of joint custody has come to the fore and it has been discussed whether joint custody can be decided upon agreement of the parties in recent years.

This review aims to introduce coparenting and joint custody and to emphasize the conditions under which joint custody benefits. For this purpose, advantages and disadvantages of joint custody and the related variables are detailed.

Parenting can be defined as a team work which requires cooperation, so coparenting refers to sharing responsibility and initiative regarding the common child, regarldless of marital status or the other relational factors (McHale, 1995). Joint custody requires the positive attitude of divorced parents towards coparenting. However, when considering the characteristics of the divorce process, there may be some difficulties and challenges.

The most important dimensions of coparenting and joint custody can be summarized as cooperation, conflict, reconciliation, comminication and support between parents. Parents can be categorized depending on these dimensions. There are various types of coparenting. The postdivorce experience of child may differ depending on this variety.
\end{abstract}


Demographic characteristics of the parents such as education level, income level, parents' education level, age and gender of the child were found to be related to their approach towards co-parenting and joint custody. In addition, relational factors such as the quality of the parents' marital relations, pre-divorce relations and conflicts between parents, characteristics related to the divorce process, the existence of another relationship or marriage, pre-divorce parent-child relations were found to be related to their approach towards co-parenting and joint custody. The factors related to the parents' personality traits and psychological conditions also effect their approach towards co-parenting and joint custody. There are comparative studies addressing in which situations joint custody is more effective than other custody arrangements. Research findings contain some contradictions; while some research findings report benefits from joint custody arrangement, some studies highlight the detrimental aspects of joint custody. It is concluded that the conflict between parents and the involvement of the child in this conflict determines whether or not to benefit from the joint custody arrangement. Bauserman (2002) suggests that joint custody should not be preferred if one of the parties is abusive or negligent, has mental health or adaptation problems, if there is a conflictual relationship and communication between the parents, as the continuous exposure of the child will increase the damage. Stability is also defined as an area that is violated in case of joint custody. Joint custody is not a model that fits all divorce situations. Therefore, it is necessary to define under which conditions and for which children joint custody will be more appropriate.

However, it is reported that there are some limitations and biases of these research. It is seen that groups representing joint custody are small and not representative, control and comparison groups are not common in studies, and longitudinal studies and follow up studies are not conducted. In addition, attention is drawn to whether the positive results of joint custody are due to joint custody itself or to pre-separation characteristics such as better cooperation, less conflict, psychologically healthier parents, or demographic characteristics such as higher education and income levels.

There are limited studies regarding coparenting and joint custody in our country because these are relatively newly developing concepts in 
Turkey. It is necessary to conduct research which will identify the current state of co-parenting and joint custody in Turkey. Recommendations and suggestions were made. Firstly, there is a neccesity for qualitative research evaluating the characteristics of parents such as difficulties, expectations, solution suggestions, and attitudes associated with coparenting during the divorce process. In addition, in order to make healthy assessments of which situations the joint custody decision is more appropriate, a model for joint custody and the assessment tools may be developed. It is thought that using multiple sources, including sample scenarios or behavioral rehearsals, may be more effective than using only self-assessment measurement tools while making predictions regarding the suitability of joint custody. Finally, before or during the joint custody process, it may be suggested to support parents with psychoeducational programs and provide additional support when necessary, and to follow the process with monitoring studies.

\section{Kaynakça / References}

Ahrons, C.R. (1994). The good divorce: Keeping your family together when your marriage comes apart. New York: HarperCollins.

Ahrons, C. R. (2007). Family ties after divorce: Long-term implications for children. Family Process, 46(1), 53-65. https://doi.org/10.1111/j.15455300.2006.00191.x.

Amato, P. R. ve Afifi, T. D. (2006). Feeling caught between parents: Adult children's relations with parents and subjective well-being. Journal of Marriage and Family, 68(1), 222-235. https://doi.org/10.1111/j.17413737.2006.00243.x.

Amato, P. R., Kane, J. B. ve James, S. (2011). Reconsidering the "good divorce". Family Relations, 60(5), 511-524. https://doi.org/10.1111/j.17413729.2011.00666.x.

Aquilino, W. S. (1994). Later life parental divorce and widowhood: Impact on young adults' assessment of parent-child relations. Journal of Marriage and the Family, 56(2), 908-922. https://doi.org/10.2307/353602.

Baude, A., Pearson, J. ve Drapeau, S. (2016) Child Adjustment in Joint Physical Custody Versus Sole Custody: A Meta-Analytic Review. Journal $\begin{array}{llll} & \text { of Divorce } \mathcal{E} \quad \text { Remarriage, } & 57(5), & 338-360\end{array}$ https://doi.org/10.1080/10502556.2016.1185203. 
Baude, A., Sagnes, F. ve Zaouche-Gaudron, C. (2010). Joint physical custody: Exploratory study with children aged 7 to 10. Dialogue, 188(2), 133146.

Baum, N. (2003). Divorce process variables and the co-parental relationship and parental role fulfillment of divorced parents. Family Process, 42(1), 117-131. https://doi.org/10.1111/j.1545-5300.2003.00117.x.

Baum, N. (2004). Typology of post-divorce parental relationships and behaviors. Journal of Divorce $\mathcal{E}$ Remarriage, 41(3-4), 53-79. https://doi.org/10.1300/J087v41n03_03.

Baum, N. ve Shnit, D. (2003). Divorced parents' conflict management styles: Self-differentiation and narcissism. Journal of Divorce $\mathcal{E}$ Remarriage, 39(3-4), 37-58. https://doi.org/10.1300/J087v39n03_02.

Bauserman, R. (2002). Child adjustment in joint custody versus sole custody. Journal of Family Psychology, 16, 91 -102 https://doi.org/10.1037/08933200.16.1.91.

Bauserman, R. (2012). A meta-analysis of parental satisfaction, adjustment, and conflict in joint custody and sole custody following divorce. Journal of Divorce $\mathcal{E}$ Remarriage, 53, 464-488. https://doi.org/10.1080/10502556.2012.682901.

Bergstrom, M., Fransson, E., Modin, B., Berlin, M., Gustafsson, P. A. ve Hjern, A. (2015). Fifty moves a year: Is there an association between joint physical custody and psychosomatic problems in children? Journal of Epidemiology and Community Health. 69(8), 769-774. http://dx.doi.org/10.1136/jech-2014-205058.

Bonach, K. (2005). Factors contributing to quality coparenting: Implications for family policy. Journal of Divorce \& Remarriage, 43(3-4), 79-103. https://doi.org/10.1300/J087v43n03_05.

Breivik, K., ve Olweus, D. (2006). Adolescent's adjustment in four postdivorce family structures: Single mother, stepfather, joint physical custody and single father families. Journal of Divorce $\mathcal{E}$ Remarriage, 44(3-4), 99-124. https://doi.org/10.1300/J087v44n03_07.

Cancian, M., Meyer, D. R., Brown, P. R., ve Cook, S. T. (2014). Who gets custody now? Dramatic changes in children's living arrangements after divorce. Demography, 51(4), 1381-1396. https://doi.org/10.1007/s13524-014-0307-8.

Carlsund, A., Eriksson, U., Löfstedt, P., ve Sellström, E. (2013). Risk behaviour in Swedish adolescents: Is shared physical custody after divorce 
a risk or a protective factor? European Journal of Public Health, 23(1), 3-8. https://doi.org/10.1093/eurpub/cks011.

Cashmore, J., Parkinson, P., Weston, R., Patulny, R., Redmond, G., Qu, L., ve Katz, I. (2010). Shared care parenting arrangements since the 2006 family law reforms (Report to the Australian Government AttorneyGeneral's Department). Sydney, Australia: Social Policy Research Centre, University of New South Wales.

Christensen, D. H. ve Rettig, K. D. (1996). The relationship of remarriage to post-divorce co-parenting. Journal of Divorce $\mathcal{E}$ Remarriage, 24(1-2), 73-88. https://doi.org/10.1300/J087v24n01_06.

Cooney, T. M., Hutchinson, K. ve Leather, D. M. (1995). Surviving the breakup? Predictors of parent-adult child relations after parental divorce. Family Relations, 44(2), 153-161. https://doi.org/10.2307/584802.

Dozier, B. S., Sollie, D. L. ve Stack, S. J. (1993). The effects of postdivorce attachment on coparenting relationships. Journal of Divorce $\mathcal{E}$ Remarriage, 19(3-4), 109-124. https://doi.org/10.1300/J087v19n03_08.

Dush, C. M. K., Kotila, L. E. ve Schoppe-Sullivan, S. J. (2011). Predictors of supportive coparenting after relationship dissolution among at-risk parents. Journal of Family Psychology, 25(3), 356-365. https://doi.org/10.1037/a0023652.

Egeren, L. A. V. ve Hawkins, D. P. (2004). Coming to terms with coparenting: Implications of definition and measurement. Journal of Adult Development, $11(3)$,

165-178 https://doi.org/10.1023/B:JADE.0000035625.74672.0b.

Emery, R. (2016). Two homes, one childhood: A parenting plan to last a lifetime. New York, NY: Avery.

Fagan, J. ve Kaufman, R. (2015). Co-parenting relationships among lowincome, unmarried parents: Perspectives of fathers in fatherhood programs. Family Court Review, 53(2), 304-316. https://doi.org/10.1111/fcre.12152.

Feinberg, M.E. (2002). Coparenting and the transition to parenthood: A framework for prevention. Clinical Child and Family Psychology Review, 5(3), 173-195. https://doi.org/10.1023/A:1019695015110.

Feinberg, M. E. (2003). The internal structure and ecological context of coparenting: A framework for research and intervention. Parenting, 3(2), 95-131. https://doi.org/10.1207/S15327922PAR0302_01. 
Feinberg, M. E., Kan, M. L. ve Hetherington, E. M. (2007). The longitudinal influence of coparenting conflict on parental negativity and adolescent maladjustment. Journal of Marriage and Family, 69(3), 687-702. https://doi.org/10.1111/j.1741-3737.2007.00400.x.

Ferrante, J. A. (2008). Co-parenting in intact and divorced families: Its impact on young adult adjustment. (Unpublished master's thesis). Virginia Commonwealth University, VA.

Frank, S., Hole, C. B., Jacobson, S., Justkowski, R. ve Huyck, M. (1986). Psychological predictors of parents' sense of confidence and control and self-versus child-focused gratifications. Developmental Psychology, 22(3), 348. https://doi.org/10.1037/0012-1649.22.3.348.

Furstenberg, F. F., Jr. ve Cherlin, A. J. (1991). Divided families: What happens to children when parents part. Cambridge, MA: Harvard University Press.

Gable, S., Belsky, J. ve Crnic, K. (1995). Coparenting during the child's 2nd year: A descriptive account. Journal of Marriage and the Family, 57(3), 609-616. https://doi.org/10.2307/353916.

Garber, B. D. (2004). Directed co-parenting intervention: Conducting childcentered interventions in parallel with highly conflicted co-parents. Professional Psychology Research and Practice, 35(1), 55-64. https://doi.org/10.1037/0735-7028.35.1.55.

Goldstein, J., Freud, A., ve Solnit, A. J. (1973). Beyond the best interests of the child. New York, NY: The Free Press.

Gürmen, S. (2019). Çocukla gelen ve hiç bitmeyen ilişki: Ortak ebeveynlik. Türk Psikoloji Yazlları, 22(44), 15-31. https://doi.org/10.31828/tpy1301996120181126m000010.

Hagquist, C. (2016). Family residency and psychosomatic problems among adolescents in Sweden: The impact of child-parent relations. Scandinavian Journal of Social Medicine, 44(1), 36-46. https://doi.org/10.1177/1403494815610664.

Hughes, F. M., Gordon, K. C. ve Gaertner, L. (2004). Predicting spouses' perceptions of their parenting alliance. Journal of Marriage and Family, 66(2), 506-514. https://doi.org/10.1111/j.1741-3737.2004.00034.x.

Jablonska, B. ve Lindberg, L. (2007). Risk behaviours, victimisation and mental distress among adolescents in different family structures. Social Psychiatry and Psychiatric Epidemiology, 42(8), 656-663. https://doi.org/10.1007/s00127-007-0210-3. 
Johnston, J., Kline, M. ve Tschann, J. (1989). Ongoing post-divorce conflict: Effects on children of joint custody and frequent access. American Journal of Orthopsychiatry, 59, 576-592. https://doi.org/10.1111/j.19390025.1989.tb02748.x.

Juby, H., Le Bourdais, C. ve Marcil-Gratton, N. (2005). Sharing roles, sharing custody? Couples' characteristics and children's living arrangements at separation. Journal of Marriage and Family, 67(1), 157-172. https://doi.org/10.1111/j.0022-2445.2005.00012.x.

Katz, L. F. ve Woodin, E. M. (2002). Hostility, hostile detachment, and conflict engagement in marriages: Effects on child and family functioning. Child Development, 73(2), 636-651. https://doi.org/10.1111/14678624.00428.

Karataş, E. (2019). Boşanmış aile çocuklarındaki uyum problemleri: Ortak ebeveynlik açısından bir inceleme. (Yayımlanmamış Yüksek Lisans Tezi.) İstanbul Üniversitesi, Sosyal Bilimler Enstitüsü, İstanbul.

Kelly, J. B. (2004). Developing beneficial parenting plan models for children following separation and divorce. Journal of American Academia of Matrimonial Law, 19, 237-254.

Kitterød, R. H. ve Lyngstad, J. (2012). Untraditional caring arrangements among parents living apart: The case of Norway. Demographic Research, 27(5), 121-152. DOI: 10.4054/DemRes.2012.27.5.

Kocayörük, E. (2010). Ergen gelişiminde aile işlevleri ve baba katılımı. Türk Psikolojik Danışma ve Rehberlik Dergisi, 4(33), 37-45.

Kolak, A. M. ve Volling, B. L. (2007). Parental expressiveness as a moderator of coparenting and marital relationship quality. Family Relations, 56(5), 467-478. https://doi.org/10.1111/j.1741-3729.2007.00474.x

Kruk, E. (1993). Promoting co-operative parenting after separation: a therapeutic/interventionist model of family mediation. Journal of Family Therapy, 15(3), 235-261. https://doi.org/10.1111/j.14676427.1993.00757.x.

Kruk, E. (2012). Arguments for an equal parental responsibility presumption in contested child custody. The American Journal of Family Therapy, 40(1), 33-55. https://doi.org/10.1080/01926187.2011.575344.

Kuzucu, Y. (2011). Değişen babalık rolü ve gelişimine etkisi. Türk Psikolojik Danışa ve Rehberlik Dergisi, 4(35), 79-91. doi:10.17066/pdrd.93674. 
Lamb, M.E. (2000). The history of research on father involvement: An overview. Marriage \& Family Review, 29(2-3), 23-42 https://doi.org/10.1300/J002v29n02_03.

Lee, M. (1997). Post-divorce interparental conflict, children's contact with both parents, children's emotional processes, and children's behavioral adjustment. Journal of Divorce and Remarriage, 27(3-4), 61-82. https://doi.org/10.1300/J087v27n03_05.

Maccoby, E. E. (1994). The role of parents in the socialization of children: An historical overview. İçinde R. D. Parke, P. A. Ornstein, J. J. Rieser, ve C. Zahn-Waxler (Eds.), A century of developmental psychology (s.589615). American Psychological Association. https://doi.org/10.1037/10155-021.

Maccoby, E. E., Depner, C. E. ve Mnookin, R. H. (1990). Coparenting in the second year after divorce. Journal of Marriage and the Family, 52, 141155 https://doi.org/10.2307/352846.

Maccoby, E.E. ve Mnookin, R.H. (1992). Dividing the child: Social \& legal dilemmas of custody. Cambridge, MA: Harvard University Press.

Macie, K.M. ve Stolberg, A.L. (2003). Assessing parenting after divorce: The co-parenting behavior questionnaire. Journal of Divorce \& Remarriage. 39. (1-2). 89-107. https://doi.org/10.1300/J087v39n01_06.

Margolin, G., Gordis, E. B. ve John, R. S. (2001). Coparenting: A link between marital conflict and parenting in two-parent families. Journal of Family Psychology, 15(1), 3-21.

Markham, M. S., Ganong, L. H. ve Coleman, M. (2007). Coparental identity and mothers' cooperation in coparental relationships. Family Relations, 56(4), 369-377. https://doi.org/10.1111/j.1741-3729.2007.00466.x.

Marriott, B. H. (2011). Coparenting and father involvement in married and unmarried co-resident couples. Journal of Marriage and Family, 73(1), 296-309. https://doi.org/10.1111/j.1741-3737.2010.00805.x.

Masardo, A. (2009). Managing shared residence in Britain and France: Questioning a default primary carer model. Içinde K. Rummery, I. Greener, \& C. Holden (Eds.), Social policy review 21: Analysis and debate in social policy, 2009 (s.197-214). Bristol: The Policy Press.

McHale, J. P. (1995). Coparenting and triadic interactions during infancy: The roles of marital distress and child gender. Developmental Psychology, 31(6), 985-996. 
McIntosh, J. E. (2009). Legislating for shared parenting: Exploring some underlying assumptions. Family Court Review, 47, 389-400. https://doi.org/10.1111/j.1744-1617.2009.01263.x.

McIntosh, J. E., Pruett, M. K., ve Kelly, J. B. (2014). Parental separation and overnight care of young children, part II: Putting theory into practice. Family Court Review, 52(2), 256-262. https://doi.org/10.1111/fcre.12088.

McIntosh, J., Smyth, B. ve Kelaher, M. (2010). Relationship between overnight care patterns and psycho-emotional development in infants and young children. Içinde J. McIntosh, B. Smyth, M. Kelaher, Y. Wells, ve C. Long (Eds.), Post-separation parenting arrangements and developmental outcomes for infants and children (s.85-168). Canberra, Australia: Report to the Australian Government Attorney-General's Departement.

McIntosh, J., Smyth, B., Wells, Y. ve Long, C. (2010). A longitudinal study of school-aged children in high-conflict divorce. Içinde J. McIntosh, B. Smyth, M. Kelaher, Y. Wells, ve C. Long (Eds.), Post-separation parenting arrangements and developmental outcomes for infants and children (s.23-84). Canberra, Australia: Report to the Australian Government Attorney-General's Department.

McLanahan, S. ve Beck, A. N. (2010). Parental relationships in fragile families. The Future of Children, 20(2), 17-37.

Minuchin, S. (1974). Families and family therapy. Cambridge, MA: Harvard University Press.

Mitcham-Smith, M. ve Henry, W. J. (2007). High-conflict divorce solutions: Parenting coordination as an innovative co-parenting intervention. The Family Journal, 15(4), 368-373. https://doi.org/10.1177/1066480707303751.

Mullett, E. K. ve Stolberg, A. (1999). The development of the co-parenting behaviors questionnaire. Journal of Divorce \& Remarriage, 31(3-4), 115-137. https://doi.org/10.1300/J087v31n03_07.

Neoh, J., ve Mellor, D. (2010). Shared parenting: Adding children's voices and their measures of adjustment to the evaluation. Journal of Child Custody, 7, 155-175. https://doi.org/10.1080/15379418.2010.512230.

Nielsen, L. (2015). Shared physical custody: Does it benefit children? Journal of the American Academy of Matrimonial Lawyers, 28, 79-139. 
Nielsen, L. (2017). Re-examining the research on parental conflict, coparenting, and custody arrangements. Psychology, Public Policy and Law, 23, 211-231. https://doi.org/10.1037/law0000109.

Parke, R.D. (2000). Father involvement: A developmental psychological perspective. Marriage $\mathcal{E}$ Family Review, 29(2-3), 43-58 https://doi.org/10.1300/J002v29n02_04.

Pearson, J., ve Thoennes, N. (1990). Custody after divorce: Demographic and attitudinal patterns. American Journal of Orthopsychiatry, 60, 233-249. https://doi.org/10.1037/h0079166.

Poortman, A.R. (2018). Postdivorce parent-child contact and child wellbeing: The importance of predivorce parental involvement. Journal of Marriage and Family, 80, 671-683. https://doi.org/10.1111/jomf.12474..

Pruett, M. K., McIntosh, J. E. ve Kelly, J. B. (2014). Parental separation and overnight care of young children, Part I: Consensus through theoretical and empirical integration. Family Court Review, 52(2), 240-255. https://doi.org/10.1111/fcre.12087.

Riina, E. M. ve Feinberg, M. E. (2018). The trajectory of coparenting relationship quality across early adolescence: Family, community, and parent gender influences. Journal of Family Psychology, 32(5), 599-609. https://doi.org/10.1037/fam0000426.

Roberson, P. N., Nalbone, D. P., Hecker, L. H. ve Miller, J. A. (2010). Adult attachment style as a predictor of coparent relationships postdivorce. Journal of Divorce $\mathcal{E}$ Remarriage, 51(3), 185-207. https://doi.org/10.1080/10502551003605619.

Roberson, P. N., Sabo, M. ve Wickel, K. (2011). Internal working models of attachment and postdivorce coparent relationships. Journal of Divorce $\mathcal{E} \quad$ Remarriage, 52(3), 187-201. https://doi.org/10.1080/10502556.2011.569442.

Russell, L. T., Beckmeyer, J. J., Coleman, M. ve Ganong, L. (2016). Perceived barriers to postdivorce coparenting: Differences between men and women and associations with coparenting behaviors. Family Relations, 65(3), 450-461. https://doi.org/10.1111/fare.12198.

Sandler, I. N., Wheeler, L. A., ve Braver, S. L. (2013). Relations of parenting quality, interparental conflict, and overnights with mental health problems of children in divorcing families with high legal conflict. Journal of Family Psychology, 27(6), 915. 
Shiller, V. M. (1986). Joint versus maternal physical custody for families with latency age boy: Parent characteristics and child adjustment. American Journal of Orthopsychiatry, 56, 486-489 https://doi.org/10.1111/j.1939-0025.1986.tb03481.x

Sobolewski, J. M., ve Amato, P. R. (2007). Parents' discord and divorce, parent-child relationships and subjective well-being in early adulthood: Is feeling close to two parents always better than feeling close to one? Social Forces, 85(3), 1105-1124. https://doi.org/10.1353/sof.2007.0056.

Sodermans, A. K., Matthijs, K. ve Swicegood, G. (2013). Characteristics of joint physical custody families in Flanders. Demographic Research, 28(29), 821-848. DOI: 10.4054/DemRes.2013.28.29.

Spruijt, E., de Goede, M. ve Vandervalk, I. (2004). Frequency of contact with nonresident fathers and adolescent well-being: A longitudinal analysis. Journal of Divorce and Remarriage, 40(3-4), 77-90 https://doi.org/10.1300/J087v40n03_05.

Spruijt, E. ve Duindam, V. (2010). Joint physical custody in the Netherlands and the well-being of children. Journal of Divorce \& Remarriage, 51(1), 65-82. https://doi.org/10.1080/10502550903423362.

Steinbach, A. (2019). Children's and parents' wellbeing in joint physical custody: A literature review. Family Process. 58(2), 353-369. https://doi.org/10.1111/famp.12372.

Stright, A. D. ve Bales, S. S. (2003). Coparenting quality: contributions of child and parent characteristics. Family Relations, 52(3), 232-240. https://doi.org/10.1111/j.1741-3729.2003.00232.x.

Teubert, D. ve Pinquart, M. (2010). The association between coparenting and child adjustment: A meta-analysis. Parenting, 10(4), 286-307. https://doi.org/10.1080/15295192.2010.492040.

Umemura, T., Christopher, C., Mann, T., Jacobvitz, D. ve Hazen, N. (2015). Coparenting problems with toddlers predict children's symptoms of psychological problems at age 7. Child Psychiatry \& Human Development, 46(6), 981-996. https://doi.org/10.1007/s10578-015-0536-0.

Vanassche, S., Sodermans, A. K., Matthijs, K. ve Swicegood, G. (2013). Commuting between two parental households: The association between joint physical custody and adolescent wellbeing following divorce. Journal of Family Studies, 19(2), 139-158. https://doi.org/10.5172/jfs.2013.19.2.139. 
Van der Heijden, F., Poortman, A.R. ve Van der Lippe, T. (2016). Children's postdivorce residence arrangements and parental experienced time pressure. Journal of Marriage and Family, 78(2), 468-481. https://doi.org/10.1111/jomf.12283.

Vanderkool, L. ve Pearson, J. (1983). Mediating divorce disputes: Mediator behaviors, styles and roles. Family Relations, 32(4), 557-566.

Van Krieken, R. (2005). The 'best interests of the child' and parental separation: On the "civilizing of parents." The Modern Law Review, 68(1), 25-48. https://doi.org/10.2307/583696.

Walker, J. (1993). Co-operative parenting post-divorce: possibility or pipedream? Journal of Family Therapy, 15(3), 273-293. https://doi.org/10.1111/j.1467-6427.1993.00759.x.

Warshak, R. A. (2014). Social science and parenting plans for young children: A consensus report. Psychology, Public Policy and Law, 20(1), 46-67. https://doi.org/10.1037/law0000005.

Whiteside, M.F. (1998).The parental alliance following divorce: An overview. Journal of Marital and Family Therapy. 24(1), 3-24. https://doi.org/10.1111/j.1752-0606.1998.tb01060.x.

\section{Kaynakça Bilgisi / Citation Information}

Sayan Karahan, A. (2021). Boşanma sürecinde ortak ebeveynlik ve ortak velayete ilişkin bir derleme. OPUS-Uluslararası Toplum Araştırmalarn Dergisi, 18(44), 8500-8523. DOI: 10.26466/opus. 970966. 